\title{
Facilitating Virtual Conferences: Reflections and Lessons Learned in Two Global Communities
}

LUKASZ PORWOL, Insight, Centre for Data Analytics, National University of Ireland, Galway

SARA S. METCALF, Department of Geography, The State University of New York at Buffalo J. BRADLEY MORRISON, Brandeis International Business School, Brandeis University

SOON AE CHUN, College of Staten Island, City University of New York

LUIS FELIPE LUNA-REYES, Rockefeller College of Public Affairs \& Policy, University at Albany

\begin{abstract}
This commentary is intended to share the authors' experiences in organizing and running two conferences fully online due to COVID-19 pandemic restrictions. We elicit key observations from these experiences and elaborate upon salient properties of the virtual mode of delivery in comparison to in-person events. We use a novel theoretical framework that combines principles of Dialogue and communication affordances of Virtual Reality to structure our discussion and align it with principles of effective online communication. We highlight the challenges and the benefits of virtual conferencing, also considering these prospects in the context of possible hybrid solutions that must adapt to the fast-changing socio-technical reality of our global communities.
\end{abstract}

CCS Concepts: • Information systems $\rightarrow$ Collaborative and social computing systems and tools;

Additional Key Words and Phrases: Virtual conference, online communication, online communities

ACM Reference format:

Lukasz Porwol, Sara S. Metcalf, J. Bradley Morrison, Soon Ae Chun, and Luis Felipe Luna-Reyes. 2021. Facilitating Virtual Conferences: Reflections and Lessons Learned in Two Global Communities. Digit. Gov.: Res. Pract. 3, 1, Article 1 (March 2022), 12 pages.

https://doi.org/10.1145/3494676

\footnotetext{
Author's address: L. Porwol, Insight Centre for Data Analytics, National University of Ireland, 49 Merrion Square, Dublin 2, D02 V583, Ireland; email: lukasz.porwol@insight-centre.org; S. S. Metcalf, Department of Geography, The State University of New York at Buffalo, 105 Wilkeson Quad, Buffalo, NY 14261-0055, USA; email: smetcalf@buffalo.edu; J. B. Morrison, Brandeis International Business School, Brandeis University, 415 South Street, Waltham, MA 02453, USA; email: bmorriso@brandeis.edu; S. Ae Chun, City University of New York, College of Staten Island, 2800 Victory Blvd, Staten Island, NY 10314, USA; email: soon.chun@csi.cuny.edu; L. F. Luna-Reyes, Rockefeller College of Public Affairs and Policy, University at Albany, 1400 Washington Av., Albany, NY 12222, USA; email: lluna-reyes@albany.edu.

Permission to make digital or hard copies of all or part of this work for personal or classroom use is granted without fee provided that copies are not made or distributed for profit or commercial advantage and that copies bear this notice and the full citation on the first page. Copyrights for components of this work owned by others than ACM must be honored. Abstracting with credit is permitted. To copy otherwise, or republish, to post on servers or to redistribute to lists, requires prior specific permission and/or a fee. Request permissions from permissions@acm.org.

(c) 2021 Association for Computing Machinery.

2639-0175/2021/03-ART1 $\$ 15.00$

https://doi.org/10.1145/3494676
}

Digital Government: Research and Practice, Vol. 3, No. 1, Article 1. Publication date: March 2022. 


\section{INTRODUCTION}

In 2020 , due to COVID-19 challenges, approximately $28 \%$ of major conferences changed to virtual mode [Falk and Hagsten 2021]. Mixed feedback is being communicated on the effectiveness of online engagements. Despite the fact that virtual conferences came about as an alternative to in-person engagements, some authors highlight the benefits of virtual modes especially in terms of accessibility and greater participation [Ahn et al. 2021; Thatcher 2006]. Literature also highlights the possibility for new ways of engagement through emerging immersive Virtual Reality technologies that otherwise would be impossible for in-person encounters [Williamson Li, and Vinayagamoorthy 2021], and even the improvement in quality of the presentations and the discussions [Thatcher 2006]. However, challenges are also reported and authors point out that while technology allows remote communication regardless of geographical location, it struggles to overcome many predominant mental models such as perception of physical distance [Bradner and Mark 2002]. A sense of community and common ground was indicated in past works as a potential solution to distance related concerns in online communication [Olson and Olson 2000].

In this commentary, we share a joint reflection on the implications of design and technology choices from two global communities that held their conferences virtually during the 2020 pandemic: the System Dynamics Society and the Digital Government Society. We guided our reflection using the integrative framework for VR-mediated consensus and community building proposed by Porwol and Ojo [2020]. Insights from these experiences, which corroborate and extend recommendations for virtual conferences by ACM [ACM Presidential Task Force 2020], may have immediate value for the design of other virtual events as public health imperatives for social distancing continue in the near term. Moreover, even after the pandemic is considered over, public and private organizations may find it beneficial to keep some of the features of the virtual experiences coupled with their in-person activity to increase the value delivered for their stakeholders in many different domains. The US Congress, for example, is already planning ahead on which virtual practices -hearings, voting, signing, etc.- may continue after the pandemic [Tully-McManus 2021].

The rest of the commentary is organized in four sections. We introduce our theoretical framework in the next section and then apply it to describe the details of both international conferences in sections three and four. We conclude with the main lessons learned from both conferences as well as reflections on how the virtual format could transform or enhance future professional conferences and activities.

\section{COMMUNICATION AFFORDANCES OF VIRTUAL SPACES}

Our conceptual framework includes all modes of digital communication and builds upon communication research linking principles of Dialogue to the Serious Communication affordances of Virtual Reality (VR) [Porwol \& Ojo 2020]. In particular, the framework leverages the Dialogue and Consensus building model [O'Neill \& Peluso 2013], which proposes four principles of dialogue grounded in the tradition of dialogue research [Bohm \& Peat 1987; Isaacs 2002]: (1) Listening, (2) Respecting, (3) Suspending, and (4) Voicing. Porwol \& Ojo [2020] extend the model discussing ways in which the Serious Communication affordances of Virtual Reality (VR) (1) Immersion, (2) Presence, and (3) Sense of Community- support each of the principles of dialogue. In the following paragraphs we define each of the VR affordances in terms of hardware, software, and socio-technical properties, briefly explaining how they support each of the principles of dialogue.

Immersion refers to the ability of a participant to join and sustain engagement in the virtual meeting in terms of access, stability of communication (minimal interruption), and quality of communication (clarity of communication channels). Strong Immersion supports the Listening principle of dialogue, where participants are able to perceive participants and follow another person's elaboration, reactions, and resistance. The affordance of Immersion is a strongly hardware-related property that depends on the technological mode of delivery. As such, immersion relies on the performance of the infrastructure and improves as the audio-visual signals between meeting participants gain in quality, smoothness, and speed [Bailenson 2021]. Depending on the technology

Digital Government: Research and Practice, Vol. 3, No. 1, Article 1. Publication date: March 2022. 
components used for online communication, immersion may relate to: (1) quality of Internet connection (latency, speed, interruptions), (2) quality of audio which may depend on the microphone and headphones/speakers type and grade, (3) quality of visuals which can relate to the type of camera, display, lighting and background used, and (4) the computing capacity of the main device, such as desktop computer, laptop, or mobile device (in case of Immersive Virtual Reality, this dimension is also linked to the type of VR headsets used with 3DOF and 6DOF, PC-dependent or standalone). Specifically, the main device may not be able to process high-quality audio-visual signals in time, creating lagging and crashing events. Relevant, strict guidelines in terms of minimal required hardware configuration may prove to be pivotal for smooth communication.

Presence refers to the degree to which the participant feels co-present with other people, allowing efficient communication and collaboration in the virtual venue. Presence is contingent on interactivity and bi-directional communication. Strong Presence supports the Suspending and the Voicing principles of dialogue, where participants switch effectively between expressing their opinion and allowing others to voice their ideas while not losing anything from the communication. Presence is a largely software-related property (with an overlap to hardware) and depends on the capacity of the software and communication platform to allow interactivity and engagement between the participants in the absence of in-person contact. Presence relates to the specific modes of synchronous and asynchronous communication that are employed to accommodate different types of engagements. In some cases, fully synchronous communication is not possible due to time-zone constraints, while asynchronous communication can deliver better results when engaging with large groups. A hybrid approach can also be applied. Therefore, this property can refer to affordances of the software platform used: availability of specific audio and video streams (including spatial data streams), chat, forums, voting, "like" features, collaborative documents and whiteboards, or other technology-specific software tools (such as virtual collaboration tools in Immersive Virtual Reality). Presence may also refer to features such as accessibility, security, authentication, user-management, and moderation capabilities. Besides specific software features, ease of use and the learning curve associated with a new software platform is a major factor that can be decisive for users to feel comfortable on the platform.

Sense of Community refers to the ability and the degree of the participant experiencing belonging and growing as part of a community. It entails basic social experience when we engage in communication with strangers around common goals. Strong Sense of Community supports the Respecting principle of dialogue, where participants are respectful to each other as part of a collective sharing a common goal. Sense of Community is an affordance of Serious Communication with a socio-technical property (with an overlap to software) that depends on the ability of participants to feel a strong sense of togetherness and common identity. To some extent, this affordance may rely on specific visual representations of participants (avatars, labels, badges), but also the specific architecture and arrangement of the virtual meeting venue, meeting organisation, and particular communication protocols. Sense of Community may also relate to the presence of elements supporting engagement and casual interactions. In the case of virtual meetings, that can be represented by a virtual coffee lounge or similar venue for promoting informal interactions and social networking.

In the following sections, we examine how these affordances were realized in virtual conferences held by two global professional societies in Summer 2020 after COVID-19 risks precluded plans for meeting in person. The first of these, the International Conference on Digital Government Research (dg.o), was designed as a mostly asynchronous conference. The second, the International System Dynamics Conference, was mostly synchronous. In considering these two virtual conference experiences and their record levels of attendance, we have come to realize that certain aspects of these virtual formats may ultimately be superior for achieving the desired affordances compared to in-person conferences. Therefore, we offer lessons for harnessing the potential of the online format to enhance virtual conferences and expand opportunities for in-person conferences to have a virtual foundation. Bringing the best of both physical and virtual worlds offers a transformative opportunity for professional societies with an international reach. 


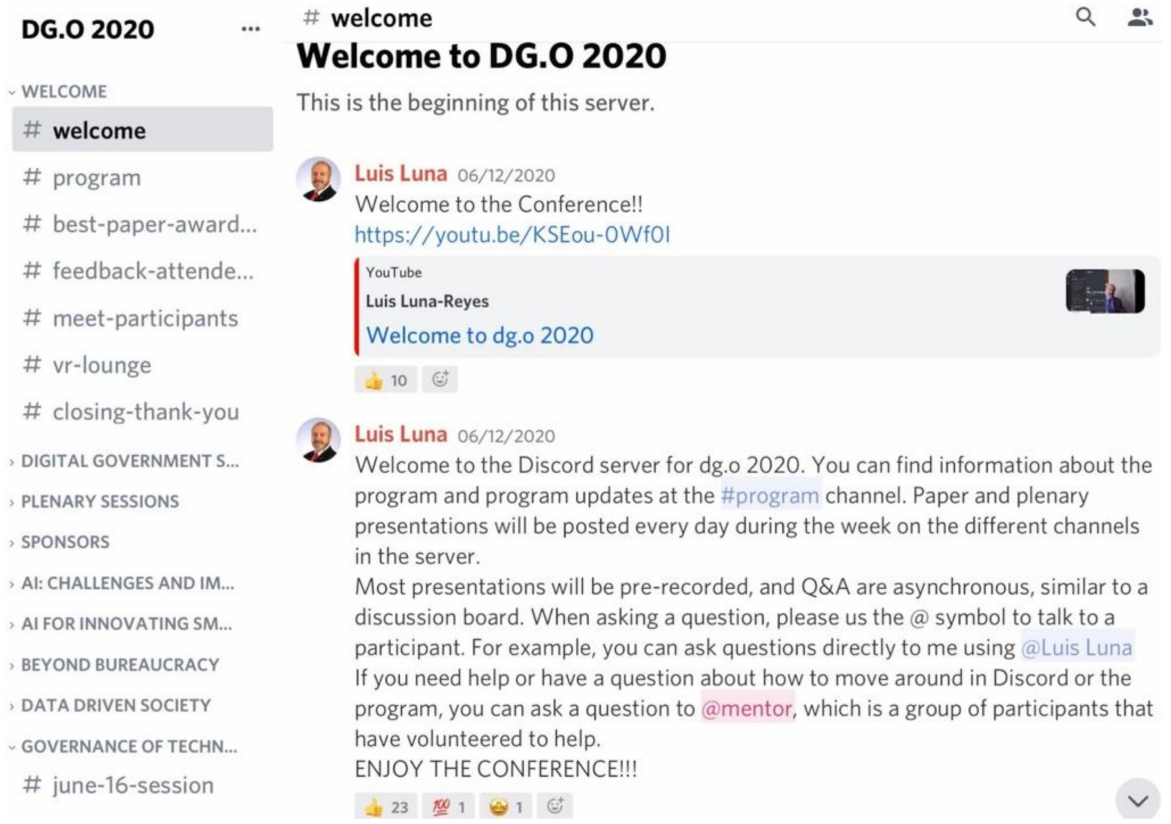

Fig. 1. DG.O channels in Discord.

\section{INTERNATIONAL RESEARCH CONFERENCE ON DIGITAL GOVERNMENT RESEARCH DG.O}

The 21st International Conference on Digital Government Research, dg.o 2020, is one of the top three digital government conferences [Scholl \& Dwivedi 2014]. The community is global in nature, including academics from Asia, the Middle East, Europe, and the Americas. Our annual Conference, dg.o 2020, took place in an online, asynchronous delivery mode using pre-recorded YouTube videos and Discord (by Mozilla) as the main platform to share content and engage in discussion (see Figure 1). We extended the Conference schedule from three to five days, and chose to post video content throughout the week, as opposed to post all content on the first day of the Conference. We also set up a Mozilla Hubs space (Virtual Reality in browser platform) to provide an opportunity for face-to-face synchronous connections among participants. A Mozilla Hubs 3-D space was integrated with our Discord server. The Conference had 121 participants for one of the largest attendances in the last few years, and featured 75 presentations including 2 keynotes, 3 guest speakers, 3 workshops, 2 tutorials, 20 posters, 5 panels, and 40 papers in parallel sessions. Conference Proceedings were published in the ACM International Conference Collection, published and made available for free to participants during the week of the Conference.

Immersion. The Conference provided a unique opportunity for participants to listen to more presentations compared to an in-person conference, and $87 \%$ of participants perceived that the event met their expectations (satisfaction survey with an $\mathrm{n}=46,38 \%$ response rate). The online delivery mode allowed for some people to participate in the conference that otherwise would have been out of their reach. One of the participants commented "I was actually pleased to be able to participate since my university budget would not permit travel to Seoul!" Another one mentioned "The virtual option makes this event accessible for all." Moreover, many participants commented on the advantages of the delivery mode to manage their own time and increased opportunities to "attend" more sessions. "I really liked being able to attend all the presentations that interested me at my convenience. The platform is excellent."

Table 1 includes the average number of video views as registered on YouTube by June 25, 2020 as a metric for immersion. Viewership is akin to attendance at an asynchronous conference, providing an indicator of 
Table 1. Immersion and Presence in dg.o as Averages of Different Forms of Participation

\begin{tabular}{|l|c|c|}
\hline Track & $\begin{array}{l}\text { Average number of views per } \\
\text { presentation (immersion) }\end{array}$ & $\begin{array}{l}\text { Average number of comments } \\
\text { per session (presence) }\end{array}$ \\
\hline AI & 15.3 & 80.0 \\
\hline Beyond Bureaucracy & 58.5 & 56.0 \\
\hline Data-driven society & 11.2 & 19.5 \\
\hline Governance of Tech & 16.0 & 7.0 \\
\hline Guest speakers & 27.7 & 18.3 \\
\hline Innovation Public services & 7.7 & 6.0 \\
\hline Keynote speakers & 46.0 & 23.0 \\
\hline Measurement & 34.5 & 8.0 \\
\hline Open Government & 11.0 & 26.0 \\
\hline Org. Factors & 27.0 & 14.0 \\
\hline Panel & 21.1 & 25.6 \\
\hline Poster & 12.5 & 67.6 \\
\hline Smart Cities & 11.5 & 40.0 \\
\hline Social Media & 19.6 & 59.5 \\
\hline Tutorial & 10.5 & 8.5 \\
\hline Workshop & 13.0 & 2.3 \\
\hline Mean & $\mathbf{1 8 . 1}$ & $\mathbf{3 0 . 9 6}$ \\
\hline
\end{tabular}

immersion to the extent that it signifies whether a presentation was seen and heard by an attendee. Not surprisingly, presentations by keynote and guest speakers received the most views and therefore the highest levels of immersion. Average views by attendees varied greatly across the program tracks. The variation in viewership does not seem to respond to any current trends in topics, and it may be explained by personal networks of presenters among conference attendees, some of which were fostered through conversations in the Discord platform. The extent of these conversations, in terms of the number of comments, is taken as an indicator of presence at an asynchronous conference, since it reflects the give and take associated with voicing and suspending aspects of dialogue.

Presence. Engaging in conversation using Discord was not equally appreciated by all conference participants. Although the software itself got good reviews from conference attendees (41/46 were satisfied with the experience), the conversations during the sessions were not equally assessed (32/46 were satisfied). This mixed feeling may be well reflected in a comment of one of the participants, "It did feel like I missed out on some of the conversations that were happening at times, but there was always the option to chime in at any time and keep the dialogue going." For some participants, the quality of the discussion could have been improved with a combination of pre-recorded presentations and live discussions. Finally, social media presence was perceived as limited by some of the conference participants.

Table 1 presents the average number of comments per track at Discord as a measure of presence. As opposed to the number of views, comments appear to be driven by topics that are attracting the attention of scholars and practitioners such as Artificial Intelligence, Social Media, and Smart Cities. Poster sessions also got a number of comments. These sessions are usually well attended also in the face-to-face conferences.

Sense of community. Creating a sense of community was maybe the most challenging task in a fully asynchronous environment where the most common representation of participants is their name and potentially their picture in a comment. Even though the core conference platform, Discord, includes tools to have synchronous conversation (audio and video), the use of these tools is not very intuitive. The tools were not used by 
participants to get together in a private channel. The conference included a couple of short synchronous ceremonies that were difficult to attend by conference participants given the time differences.

In addition, we created a Mozilla Hubs virtual venue with the purpose of providing a place for informal gatherings involving conference participants. Once more, maybe because of the lack of more clear mechanisms to coordinate and gather together, the virtual space was not very successful. As one of the participants commented in his assessment of the conference, "I had the chance of learning about [different topics] more than on other face to face events, although I did miss the chance of meeting with friends and colleagues." Another one commented, "I believe this year's conference could not provide opportunities to connect to others."

Maybe the most successful effort to create a sense of community was the traditional group picture, which this year was made using a collage of headshots in the virtual wall of the Mozilla Hubs virtual space. The activity may point to the potential of a more intensive use of this area.

\section{INTERNATIONAL SYSTEM DYNAMICS CONFERENCE}

The 38th annual International System Dynamics Conference was to be held in Bergen, Norway in July 2020, exactly 20 years after the last such conference was held there. Prior to the COVID-19 pandemic, plans were already in place to pilot virtual live streaming of certain conference sessions to promote accessibility beyond those who could attend in person. The decision to plan for an entirely virtual conference was made in March 2020 shortly after the submission deadline had passed. By May 2020, the broad contours of the virtual conference format were determined: sessions would be delivered live via Zoom on an extended synchronous Bergen schedule; most sessions would be recorded and retained two weeks beyond closing of the live conference; and "echo" discussion sessions were introduced to expand opportunities for synchronous dialogue about presentations given earlier. A custom 3-D application was designed for the conference that enabled participants to speak synchronously, listen to virtually proximate conversations, and interact with certain posters and videos in a 3-D Bergen landscape.

This inaugural virtual conference of the System Dynamics Society ultimately drew a record 679 registered participants, $121 \%$ higher than the previous record of 559 attendees set in 2007. Despite the shift to the virtual format, the categories for presentation of author contributions remained the same as they would have been for the in-person conference: there were 8 plenary sessions (including an opening COVID-19 plenary that was free to the public), 38 parallel sessions, 20 work in progress sessions, 68 poster presentations, 25 workshops, 5 roundtable discussions, and 4 discussant-led feedback sessions. Although expectations for the event were mixed, most sessions were executed without mishap, and participants expressed a strong interest in continuing a virtual option for future conferences. In the discussion that follows, we reflect on the nature of the conference experience according to the affordances of Immersion, Presence, and Sense of Community.

Immersion. A custom website was developed for the main conference interface with convenient links to attend live Zoom sessions, view video recordings, and access papers, models, and presentation materials. The conference website could be accessed on any web browser, which facilitated a foundational level of immersion.

Live Zoom meetings were held in webinar format for plenary sessions and in meeting format for parallel sessions, posters, feedback discussions, roundtable discussions, and "echo" discussion sessions. In each of the Zoom sessions, immersion was moderated by the ability of participants to access the platform from various devices. Zoom accessibility was generally robust for presenters, although some connectivity issues were encountered (e.g., country-specific constraints on Internet access).

Presenting authors were encouraged to pre-record their presentations so that they could be made available via YouTube links on the conference website. This enabled a backup option if technical difficulties interfered with live presentation. Such pre-recordings also enabled previewing and preparing for a deeper level of engagement with the subject by the audience. However, even if a talk was pre-recorded, live presentations were encouraged when feasible so as to facilitate engagement and interactivity of the conference experience.

The 3-D app of Virtual Bergen created an immersive environment in which participants could talk with those in their virtual vicinity. However, since the app required more sophisticated hardware to install and operate

Digital Government: Research and Practice, Vol. 3, No. 1, Article 1. Publication date: March 2022. 


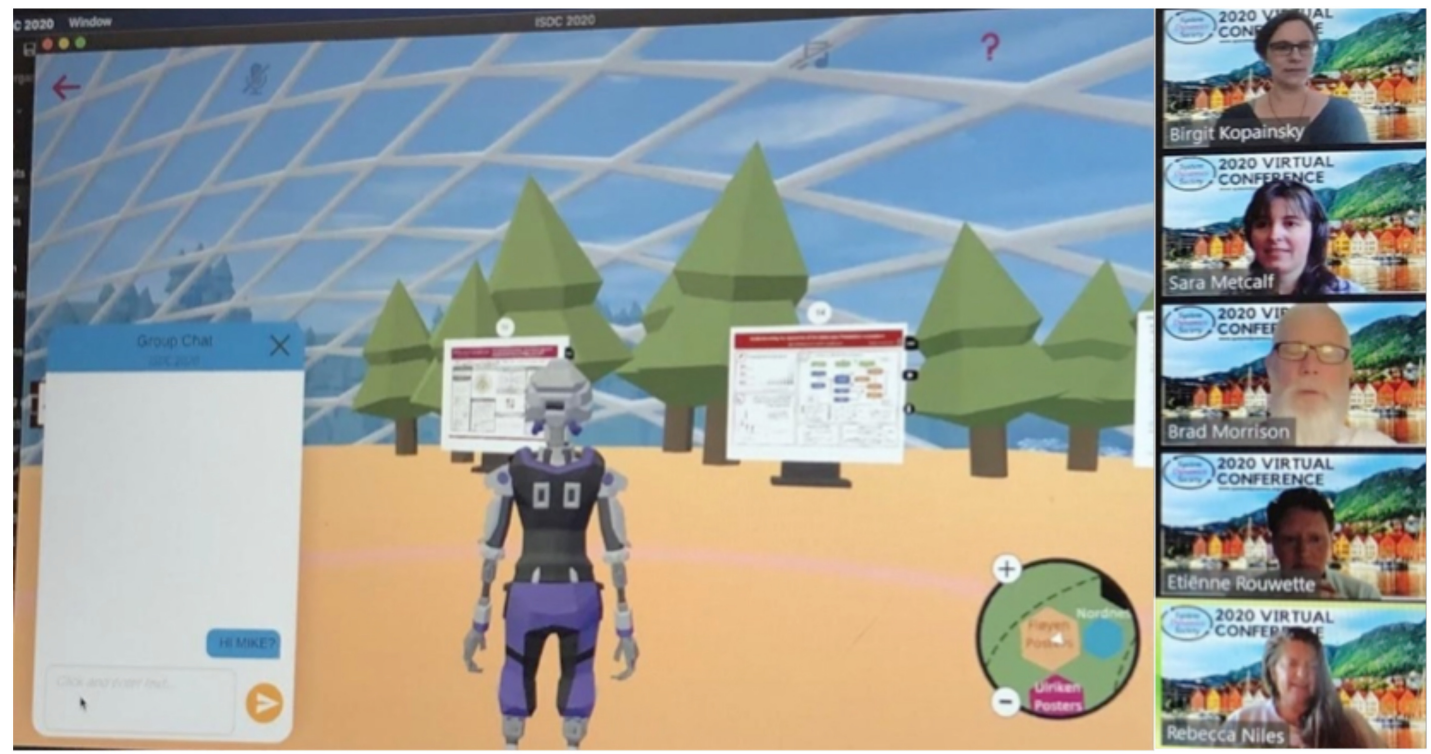

Fig. 2. View of the 3-D app (left panel) in a Zoom meeting of the virtual conference team.

properly, it was not experienced fully by all participants (in a post-conference survey, $70 \%$ of respondents indicated that they used the 3-D app). Although switching to the 3-D app from the main website compounded cognitive load, much enthusiasm was expressed through the added layers of Virtual Reality that were enabled by the 3-D app, such as for the student posters and sponsor displays. Figure 2 shows the conference organizers demonstrating the 3-D environment in a Zoom meeting.

Presence. To offset the loss of a physical conference site, the conference organizers referred to "Virtual Bergen" as the event "location" in promoting the event and announcements to attendees. A simple component of promoting a shared sense of presence at the virtual conference was the use of a common Zoom background with the iconic Bergen backdrop by many of the organizers, session chairs, and other conference participants (See Figure 2).

Elements of presence pertaining to time include duration, continuity, and mishaps from simultaneity (e.g., scheduling two events in the same room). The duration of the live conference was extended from four to five weekdays, from July 20-24, preceded by a Sunday pre-conference colloquium organized by the student chapter, and a virtual Summer School the week beforehand. The conference website was available for two weeks after the end of the live conference so that attendees could continue to view materials and recordings of sessions they might have missed or wished to review.

A design goal of the synchronous virtual conference was to allow for sufficient buffer time between sessions, while maintaining a broader level of continuity over time (i.e., have breaks, but not too long, so that participants have an incentive to stick around for more) and accessibility for participants across time zones.

Consideration of time zone accessibility was an important criterion for scheduling the live program. While live sessions anchored to Bergen time formed the backbone of the virtual conference, shorter "echo" discussion sessions were scheduled at "opposite" times (about 12 hours later than the original session) to enable synchronous dialogue among participants across world time zones. These sessions were specifically intended to encourage live discussion among participants who were not available for the original session. Although presenters were not expected to attend these sessions, they were encouraged to do so if possible and frequently did attend. These sessions then allowed for deeper discussions among a smaller set of attendees than at the original presentation. 
One challenge of live virtual presentation was the need to keep to schedule without the ability to interrupt visually (since the use of the chat or nonverbal signals were unreliably visible to presenters in screen share mode), requiring verbal interruptions by session chairs about time remaining. Effective voicing of interruptions by the chair during presentation required a momentary suspension of the presenter's voice and thereby a momentary disruption to the presence experienced by session participants. In contrast, for presenters delivering a talk in a physical meeting room, signs about time remaining could be quietly held up by session chairs without disrupting the speaker.

A particularly acute challenge of synchronous delivery was to budget for sufficient transition time between sessions. Presenters and session chairs were asked to arrive 25 minutes early to virtual "green rooms" for testing audio-visual connection and slide sharing capabilities, so any previous sessions in those rooms needed to be completed on time. The schedule was therefore more rigid than might be feasible for an in-person conference, where participants in one session may linger as attendees of the subsequent session start to arrive. Allowing an alternative space for participants to network in a different virtual meeting room or voice channel would confer the benefits of a coffee hour in allowing time for room organizers and presenters to get ready for the next session.

Sense of Community. Certain tools were available to facilitate networking among conference participants. A participant page on the conference website was included and pictures and bios were provided and linked to sessions for which participants were scheduled as presenting authors or session chairs. A comment feature was also available for each presentation on the conference website, but many participants were not aware of it, and it was not highly utilized during the conference.

The chat function of Zoom was most frequently used to promote interaction between participants and presenters, particularly via session chairs soliciting questions for presenters. However, each chat was restricted to the session. An opportunity to expand the chat feature asynchronously between sessions, such as via a tool like Discord, would help to promote a fuller Sense of Community among participants.

Chat capabilities were also available in the 3-D app and were helpful for directing participants to navigate to event locations. Audio features in the 3-D app contributed a conference-like sense of community from the serendipitous synchronicity of "bumping into" others in the virtual sphere.

Another aspect of the live conference experience was the provision of daily morning announcements about the program ahead. In lieu of such live announcements, the conference organizers decided to issue daily email blasts as "morning messages" at an early Bergen time. Additional emails were also sent as needed during the conference to make clarifications and announcements, such as when a mishap occurred due to simultaneous room use in the opening plenary, but care was taken to avoid email overload.

The ability of the virtual conference to foster a Sense of Community was not known ahead of time, and some scepticism surrounded the virtual shift as would-be conference-goers lamented the loss of opportunities for inperson networking at the carefully chosen venue of beautiful Bergen. However, the increased accessibility of the conference (through the virtual format and the discounted cost of attendance) resulted in record levels of participation. While $58 \%$ of conference survey respondents still indicated that they would prefer an in-person conference to virtual, those who had participated in one previous conference were evenly split (50\%) in their preferences for virtual and face-to-face formats. Among the respondents who did not express an opinion on the format, many left comments indicating a desire for hybrid conferences, such as: "Next conferences should have joint face-to-face and virtual formats!"

A strong Sense of Community was evident during conversations in special plenaries such as the presidential address (available at https://youtu.be/iL24d2a2uXY) and the conference closing ceremony, both of which generated an abundance of chat messages in Zoom. The closing ceremony included a montage of photo submissions from participants showing how they were engaging with the virtual environment in a myriad of real-world contexts: https://youtu.be/V9nqbMZrung. 
Table 2. Serious Communication Affordances by Conference Type

\begin{tabular}{|c|c|c|c|}
\hline Affordance & In-person Conference & $\begin{array}{l}\text { Asynchronous Virtual } \\
\text { Conference }\end{array}$ & $\begin{array}{l}\text { Synchronous Virtual } \\
\text { Conference }\end{array}$ \\
\hline Immersion & $\begin{array}{l}\text { Conditional on } \\
\text { conference venue } \\
\text { attributes such as } \\
\text { geographic location, } \\
\text { meeting rooms and AV } \\
\text { equipment. }\end{array}$ & $\begin{array}{l}\text { Use of Virtual sites or } \\
\text { platforms (e.g., Discord) to } \\
\text { facilitate viewing of } \\
\text { recorded sessions within } \\
\text { organized chat threads. }\end{array}$ & $\begin{array}{l}\text { Attendance at live virtual } \\
\text { meeting sessions, } \\
\text { use of VR 3D app for } \\
\text { special events, and access } \\
\text { to conference website. }\end{array}$ \\
\hline Presence & $\begin{array}{l}\text { In-person gathering is } \\
\text { the "gold standard", } \\
\text { although limited by time } \\
\text { and space. }\end{array}$ & $\begin{array}{l}\text { Pre-recorded presentations } \\
\text { allow for strong voicing } \\
\text { potential. The recorded } \\
\text { contents and } \\
\text { chat/commenting } \\
\text { capabilities provide } \\
\text { exploration of questions } \\
\text { and connecting } \\
\text { participants, breaking the } \\
\text { limits of time and space. }\end{array}$ & $\begin{array}{l}\text { Potential is as strong as the } \\
\text { capability of the platform } \\
\text { (e.g., Zoom) and how it is } \\
\text { used (i.e., session } \\
\text { moderation). It breaks the } \\
\text { limit of space, but is still } \\
\text { limited by time. }\end{array}$ \\
\hline $\begin{array}{l}\text { Sense of } \\
\text { Community }\end{array}$ & $\begin{array}{l}\text { Generally strong from } \\
\text { opportunities to } \\
\text { socialize and network at } \\
\text { conference events such } \\
\text { as poster sessions, coffee } \\
\text { hours, banquets, etc. } \\
\text { Limited to participants } \\
\text { who are able to attend in } \\
\text { person. Facilitation } \\
\text { design plays a key role } \\
\text { across modalities. }\end{array}$ & $\begin{array}{l}\text { Virtual format has the } \\
\text { potential to enable greater } \\
\text { interaction. More can be } \\
\text { said in chat, it is easier to } \\
\text { express, it is more } \\
\text { accessible, it is more } \\
\text { democratic, and } \\
\text { participants may share } \\
\text { useful information and } \\
\text { hyperlinks. Persistence of } \\
\text { online record enables a } \\
\text { sense of community to } \\
\text { extend the conference } \\
\text { experience beyond the } \\
\text { event at a point in time. }\end{array}$ & $\begin{array}{l}\text { Potential for "flattening" } \\
\text { power dynamics and } \\
\text { equalizing international } \\
\text { communities. Feeling of } \\
\text { proximity from video } \\
\text { conferencing. Chat } \\
\text { messages add to participant } \\
\text { experiences during live } \\
\text { sessions, and some may } \\
\text { find it easier to type than } \\
\text { unmute to ask questions. } \\
\text { Additional discussion } \\
\text { sessions used to include } \\
\text { participants across time } \\
\text { zones. }\end{array}$ \\
\hline
\end{tabular}

\section{LESSONS LEARNED AND CONCLUSIONS}

Moving in-person conferences to the virtual sphere had both positive and negative consequences in the communication process and the results. Drawing upon the communication affordances discussed above, we conclude with reflections from our two conferences.

Table 2 highlights how these affordances were experienced in traditional in-person conferences and virtual conferences of the asynchronous and synchronous variety, as exemplified by the dg.o and ISDC events, respectively. Ties to a physical place make an in-person conference generally more favorable for presence and sense of community. However, opening up to the virtual sphere expands opportunities for immersion through ease of attendance and its associated benefits, beyond what is possible with a physical venue.

Technology platforms and pre-recorded presentations contributed, at least in the two communities included in this note, increased immersion of participants in the conference and were generally appreciated by participants. 
Participants in these two conferences appreciated in particular the fact that they could "attend" more sessions than in a face-to-face conference, and they particularly enjoyed the fact that presentations remained available for a window longer than the duration of the conference. Given that participants did not need to physically move to the conference site and the reduction of the cost of physical infrastructure to run the conference, the cost of attending the conference was significantly lower. As a consequence, more members of both communities were able to attend the meetings.

In terms of presence in the conversation, the use of new software to participate involved a learning curve that produced a slow start of the events. Once participants got familiar with the new technology, they were able to be present in the conferences. As we have all experienced in the last year, participating in virtual meetings through technology platforms produces some form of fatigue that may have impacted participants' presence in discussions and also the fluctuations in participation observed in the digital government community. Synchronous scheduling is an issue particularly relevant for the case of global communities like the ones included in this note. In addition to recording live sessions, scheduling "echo" sessions at different times for additional discussion was used to promote inclusion for global attendees at the system dynamics conference. Nonetheless, fatigue was also identified as an important issue.

In terms of a sense of community, participants in both conferences expressed the need for more opportunities for informal communication and informal ways of engagement that usually take place in breaks or informal gatherings during the conference. Participants in the digital government community missed having synchronous events as part of the conference. The use of a 3-D space in the system dynamics conference was attractive for a set of users; looking at themselves represented as an avatar had a positive impact in their interactions with others in this 3-D space.

In addition, although the overall experience in both conferences last year could be considered a positive one, after a year of virtual life it is very possible that expectations from participants are higher this year. During the COVID-19 pandemic of 2020, many people were just happy to have the possibility of participation in global events, but fatigue and distress produced by social distancing and the continuous immersion in the virtual world will have an impact on events in the future.

Using the affordances introduced above, we close this reflection with some considerations for future virtual conferences. We find that the fundamental affordance to consider for any online event is Immersion, as a key to enabling and maximizing accessibility for global attendees. Immersion is highly dependent on technology but is driven by relevant socio-technical approaches. Specifically, while it is important for participants to have sufficient broadband connectivity and good quality interfaces (microphone, speakers, camera, screen), on the organizer side what matters is the relevant interplay of synchronous participation (represented by teleconferencing live sessions) with efficient asynchronous communication channels. This affordance is particularly important when considering the wide geographical distribution of users and challenges related to different time zones in international events. Organizers are encouraged to arrange live sessions in a way that allows globally diverse attendees to engage in dialogue from across different time zones. This could be done by allowing additional discussion time, compressing live presentations into a smaller window of time accessible by most attendees. An approach in which the sessions were compressed has proved to be very engaging for our events. Those observations are in line with recommendations by ACM [ACM Presidential Task Force 2020]. Additionally, we observed that the use of pre-recorded presentations as well as recording the sessions and providing relevant audio transcripts to audiences asynchronously significantly improved the availability of the content to a wider audience. Such availability was largely appreciated. In this context, setting clear guidelines for intellectual property management in sharing videos upfront is pivotal for a seamless experience.

Once Immersion is ensured, Presence is the core affordance to ensure user participation and rich interactions. This affordance relates strongly to the software platforms leveraged to facilitate interaction, but its success is predicated on the active management (e.g., muting) of participants in those systems. Our experience underscores the importance of both using familiar platforms that require a minimal learning curve and providing full technical

Digital Government: Research and Practice, Vol. 3, No. 1, Article 1. Publication date: March 2022. 
support for session moderators at all times. Even so, we recommend including orientations and tutorials on how to get the best of the platforms for the conference. Sessions should be well rehearsed, and presenters' software settings (such as a virtual background and green screen) should be tested in advance to avoid taking time away from other participants online. In terms of interactivity, tools such as chats, polls, breakout rooms, and emojis can enhance online participation and increase user engagement.

The final affordance, Sense of Community, is strongly related to the socio-technical aspects of considering online conferences. Sense of Community can be expressed as the capacity of the platform and the capability of the event management to facilitate professional networking. Our experience suggests that combining synchronous and asynchronous opportunities for interaction is ideal for an international event. For example, allowing online platforms to be accessible 24/7 and scheduling time for social networking during session breaks can facilitate side-meetings and promote community building. The use of online message boards to support coordination of smaller gatherings in virtual spaces, a participant directory with linked sessions, and other features of the online format can further enrich the sense of community among participants. Additionally, the use of chat tools allowed participants to engage in a way suiting their personal preferences. To ensure the strong community spirit, clear rules of engagement, respectful conversation, privacy and security matters should be established up front and updated as needed for specific online communication modes.

The necessity of virtual meetings during the COVID-19 pandemic has increased our familiarity with many of the current collaboration and communication technical platforms. Both conference experiences suggest that delivering academic and professional conferences using a hybrid design including in-person events along with opportunities for virtual participation may be the most effective way to reach diverse global communities. Virtual conferences are also changing normative modes of participation. Attending a conference from home or the office is significantly different from traveling to a conference venue. Work and personal-related demands thus have a larger impact on participant immersion in the conference. These differences need to be considered in the light of potential attendee characteristics to strike the best balance of synchronous and asynchronous online activities.

A key takeaway from these reflections is that the process of choosing which online platforms to use for a virtual conference, and determining how to use them, should consider these communication affordances (immersion, presence, and sense of community) so as to maximize the potential for dialogue. We believe that - even in a post-pandemic world when pandemic restrictions end - virtual conference experiences provide an opportunity to reflect on the future of academic conferences. In-person components are quite important, at least in the view of many members of our two communities, but the global experience of the last year and a half invites us to reimagine the future of academic and professional meetings [Etzion et al. 2021]. In person experiences may be designed to maximize opportunities to connect with others and engage in conversation, but keeping some of the characteristics of virtual events, such as the pre-recorded presentations, in a form of hybrid experience, has great potential to increase both the quantity and quality of opportunities to engage in academic and professional conversations. Experimenting with and assessing these hybrid modes of academic and professional meetings will be necessary to fully understand the advantages and value of virtual and in-person interactions.

\section{ACKNOWLEDGMENTS}

We wish to thank the many conference organizers, volunteers, sponsors, and participants who, by a leap of faith, enabled these virtual conference experiments to happen in the first place. We are also grateful to the editor and the reviewer for helpful feedback that has improved this manuscript.

\section{REFERENCES}

ACM Presidential Task Force. 2020. Virtual conferences: A guide to best practices.

Sun Joo (Grace) Ahn 2021. IEEEVR2020: Exploring the first steps toward standalone virtual conferences. Frontiers in Virtual Reality 2 (April). D. Bohm and F. D. Peat. 1987. Science, order and creativity. In Science, Order and Creativity. 
J. N. Bailenson. 2021. Nonverbal overload: A theoretical argument for the causes of Zoom fatigue. Technology, Mind, and Behavior 2, 1 (2021) https://doi.org/10.1037/tmb0000030

Erin Bradner and Gloria Mark. 2002. Why distance matters: effects on cooperation, persuasion and deception. In Proceedings of the 2002 ACM conference on Computer supported cooperative work (CSCW'02). Association for Computing Machinery, New York, NY, USA, 226-235. DOI: https://doi.org/10.1145/587078.587110

Etzion Dror, Joel Gehman, and Gerald F. Davis. 2021. Reimagining academic conferences: Toward a federated model of conferencing. Management Learning. Ahead of print, 14 DOI : https://doi.org/10.1177/13505076211019529

Martin Thomas Falk and Eva Hagsten. 2021. When international academic conferences go virtual. Scientometrics 126, 1 (2021), 707-24. https://doi.org/10.1007/s11192-020-03754-5

W. Isaacs. 2002. Dialogue and the art of thinking together. In fournal of Organizational Change Management (15).

Gary M. Olson and Judith S. Olson. 2000. Distance matters. Human-Computer Interaction 15 (2-3), 139-78.

S. A. O'Neill and D. C. C. Peluso. 2013. Using dialogue and digital media composing to enhance and develop artistic creativity, creative collaborations and multimodal practices. Developing Creativities in Higher Music Education: International Perspectives and Practices, January 2013, 115-126. https://doi.org/10.4324/9781315885223

L. Porwol and A. Ojo. 2020. VR-participation \& dialogue: Towards integrated framework for virtual reality-mediated consensus and community building. ACM International Conference Proceeding Series 24-30. https://doi.org/10.1145/3396956.3398259

Hans J. (Jochen) Scholl and Y. K. Dwivedi. 2014. Forums for electronic government scholars: Insights from a 2012/2013 study. Government Information Quarterly 31, 2 (2014), 229-242. https://doi.org/10.1016/j.giq.2013.10.008

Andrew Thatcher. 2006. Building and maintaining an online academic conference series. International fournal of Industrial Ergonomics 36, 12 (2006), 1081-1088. DOI : https://doi.org/10.1016/j.ergon.2006.09.009

K. Tully-McManus. 2021. Planning for a post-pandemic Congress underway. Roll Call. https://www.rollcall.com/2021/03/11/planning-for-apost-pandemic-congress-under-way/.

Julie R. Williamson, Jie Li, and Vinoba Vinayagamoorthy. 2021. Proxemics and social interactions in an instrumented virtual reality workshop. Conference on Human Factors in Computing Systems - Proceedings.

Received May 2021; revised September 2021; accepted October 2021

Digital Government: Research and Practice, Vol. 3, No. 1, Article 1. Publication date: March 2022. 